\title{
Precancerous Cervical Lesions and Associated Factors Among Women Attending Cervical Screening at Adama Hospital Medical College, Central Ethiopia
}

This article was published in the following Dove Press journal:

Cancer Management and Research

\author{
Desalegn Merera' \\ Gebi Husein Jima $\mathbb{D}^{2}$ \\ 'Oromia Regional Health Bureau, Adama, \\ Ethiopia; '2Department of Public Health, \\ College of Health Science, Arsi \\ University, Asella, Ethiopia
}

Background: Cervical cancer is the third most common form of cancer among women worldwide. Yet it is one of the few cancers that can be detected and prevented at precancerous stage. Even though different studies were conducted in different areas in Ethiopia, the risk factors for cervical precancerous lesions in the Ethiopian setting are not well identified. Purpose: To determine prevalence of precancerous cervical lesion and associated factors among women of reproductive age group attending screening center at Adama Hospital and Medical College.

Patients and Methods: A cross-sectional study was carried out from June 11 to July 11, 2019. Data was collected through interview aided questionnaires and visual inspection with acetic acid applied for screening and treatment. A random sample of 293 were included in the study. Data was entered into Epi Info version 7, and analyzed by SPSS version 21. Descriptive analysis was conducted to describe the study population and a logistic regression analysis was applied to assess the association of independent variables with the outcome variable. The level of significance of association was determined at $\mathrm{p}$ - value $<0.05$.

Results: Out of the total 293 screened women, $15.7 \%$ (95\% CI: $11.3 \%-20.1 \%$ ) were found to be positive for precancerous cervical lesion. After controlling for the effect of other confounding factors, four variables, absence of menses (adjusted odds ratio $(\mathrm{AOR})=0.18$, $95 \%$ CI $(0.04,0.87))$, history of pelvic infection $[\mathrm{AOR}=2.82 ; 95 \% \mathrm{CI}(1.21,6.59)]$, history of STI $[\mathrm{AOR}=2.65 ; 95 \% \mathrm{CI}(1.26,5.56)]$ and having a partner who had another partner $[\mathrm{AOR}=2.41 ; 95 \% \mathrm{CI}(1.08,5.38)]$ were found to be significantly associated with precancerous cervical cancer at cut-off point p-value less than 0.05 .

Conclusion: Menstrual history, history of pelvic infection, history of STI, and had a partner who had another partner were found to be significantly associated with precancerous cervical lesion.

Keywords: pre-carcinoma, cervix, adult women, screening study, factors, Ethiopia

\section{Background}

Cancer is a general term used to refer to a condition in which the body's cells begin to grow and reproduce in an uncontrollable way. ${ }^{1}$ Persistent infection with cancercausing HPV types is the cause of most cervical cancer. ${ }^{2}$ Cervical pre-cancer is a distinct change in the epithelial cells of the transformation zone of the cervix; the cells begin developing in an abnormal fashion in the presence of persistent or longterm HPV infection. ${ }^{2}$
Correspondence: Gebi Husein Jima Departments of Public Health, College of Health Science, Arsi University, P.O. Box: 04, Asella, Ethiopia

Tel +25I-9l0-76-4I-29

Email gebihussein@gmail.com 
According to Globocan (estimates for 2018), there were 569,847 new cases and 311,365 deaths of cervical cancer in 2018 worldwide. Cervical cancer is the second most common cancer in women living in less developed regions. Both the incidences and deaths (90\%) are occurring in low and middle-income countries. ${ }^{3}$

According to Globocan, there were about 6,294 newly diagnosed cervical cancer cases and 4,884 cervical cancer deaths in 2018 (estimates for 2018) in Ethiopia, accounting for about $11.7 \%$ and $15.3 \%$ of total cancer cases and deaths in females, respectively. It is the second most commonly diagnosed cancer as well as the second leading cause of cancer related deaths in Ethiopia. ${ }^{3}$

Cervical cancer (CC) is usually developed after a prolonged phase of pre-invasive lesions in the cervix. Therefore, early identification and treatment at its preinvasive stage may benefit the clients and decrease the burden of morbidity and mortality resulting from cervical cancer. $^{4}$

Visual Inspection with Acetic Acid (VIA) is one of the screening modalities of cervical pre-cancerous lesion. ${ }^{5}$ Screening with VIA in resource limited setting is the commonly preferred method compared to Human Papilloma Virus (HPV) test and cytological or Pap smear. This is because it does not need more advanced testing requirements (trained cytotechnicians or pathologists) and other program requirements. ${ }^{6}$

Recently in Ethiopia, cervical cancer screening centers are being established to provide screening services for all eligible women. It had reported VIA sensitivity for detecting precancerous lesions comparable to or greater than cervical cytology, while requiring fewer resources and feasible to carry out in low level health facilities. In addition, VIA provides immediate results, thus promoting linkage of screening with treatment. This "see and treat" method ensures adherence to treatment soon after diagnosis, and reduces the risk that women will get lost in the referral system. VIA combined with cryotherapy (freezing of precancerous lesions of the cervix), ideally a single visit approach (SVA), is an effective and efficient strategy for secondary prevention of cervical cancer in low resource settings, and can be conducted by competent clinicians and nurses. ${ }^{7}$

Evidence has shown that in the South-East Asia Region mortality rates from cervical cancer are very high due to the late stage at diagnosis and suboptimal therapeutic facilities which justifies the importance of VIA. ${ }^{8}$
Detection of cancer at an early stage may be considered as a marker for access to health care and preventive health services, including cervical cancer screening. Both incidence and mortality can be reduced by detecting precancerous lesions then prompt treatment which can prevent its progression, thereby increasing patient survival. ${ }^{9}$

Routine access to cervical cancer screening was not available and treatment for precancerous cervical lesions did not exist in Ethiopia until implementation of the Addis Tesfa project in 2009. ${ }^{10}$

The National Cancer Control Plan is a response by the FMoH and stakeholders to prioritize cancer Control in Ethiopia. The strategy aims to promote cancer prevention and early detection, and to improve diagnosis and treatment, including palliative care. It also aims to promote cancer surveillance, registration and research. The country has achieved some activities through this strategy such as cervical cancer information dissemination for community through health extension workers, HPV vaccination for before sexually active girls and expansion of cancer treatment services. ${ }^{1}$ The Ethiopian Health Sector Development Plan IV (HSDP-IV) is a policy in Ethiopia which includes the prevention and control of cancer. ${ }^{11}$ Based on this policy guidance, Federal Ministry of Health(FMoH) has recently designed and developed a national guideline on prevention and control of cancer. $^{7}$

Identifying factors associated with the precancerous cervical lesion is important for planning a more targeted screening program to decrease the high morbidity and mortality of the disease in the country. However, the risk factors for cervical precancerous lesions among the general population in the setting of Ethiopia are not well identified. This study, therefore, aimed to find out the prevalence of precancerous lesion and associated factors among women of reproductive age group attending Adama Hospital and Medical College (Figure 1).

\section{Methods}

\section{Study Area}

The study was conducted at Adama Hospital and Medical College which is a regional referral hospital established 77 years ago (1946). It is one of the hospitals in Oromia with a high patient load and located at Adama town. It is about $98 \mathrm{~km}$ east of Addis Ababa. Adama hospital and Medical College started cancer screening in 2010 E.C and serves as referral center for surrounding health centers. 


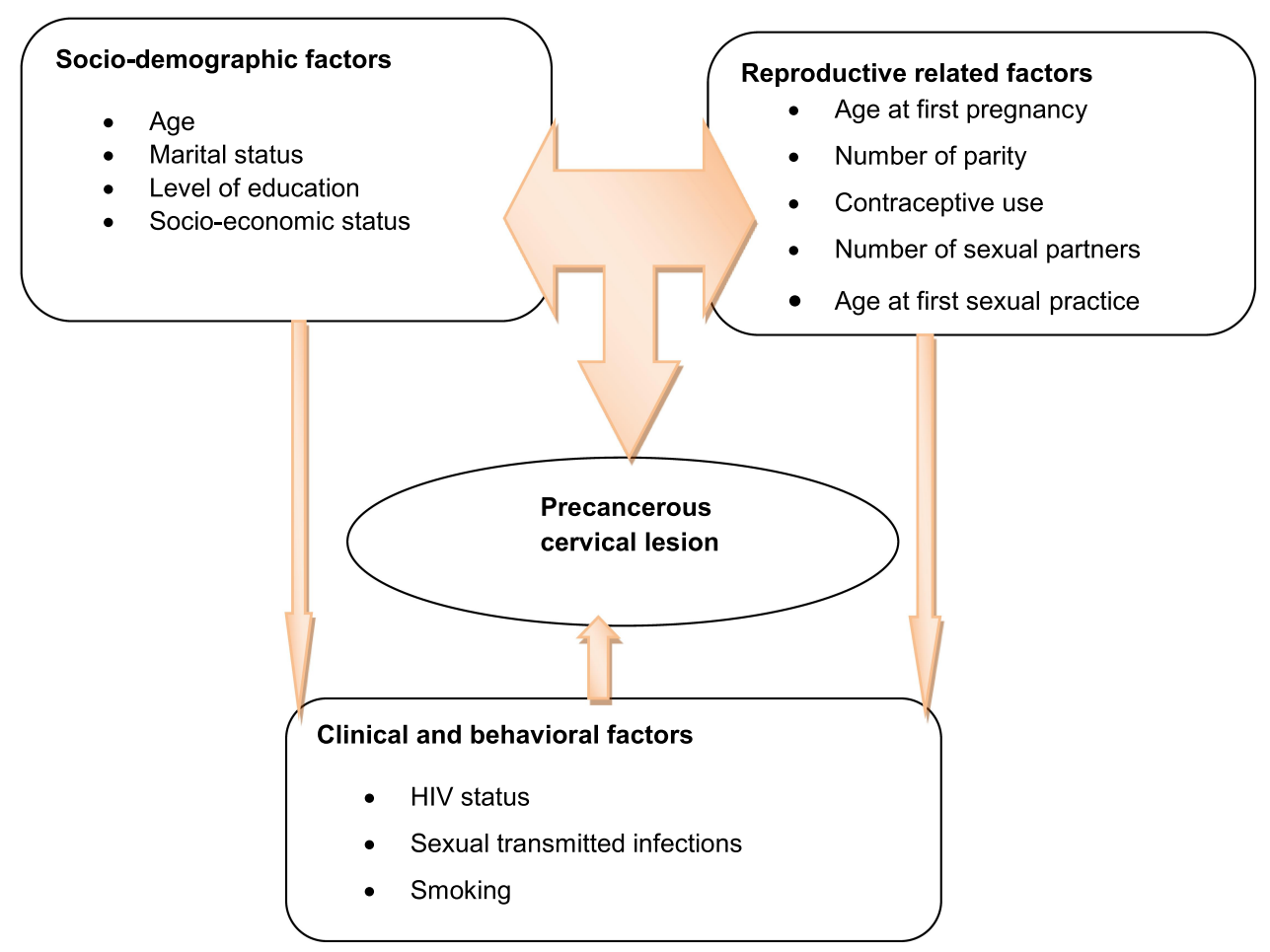

Figure I Conceptual framework of the study.

\section{Study Design and Period}

Hospital based cross-sectional study was carried out from June11 to July 11, 2019.

\section{Source Population}

The source population was all women of reproductive age group who came for cervical cancer screening.

\section{Study Population}

The study population was all women of reproductive age group who came for cervical cancer screening at Adama Hospital Medical College cervical screening center during study period.

\section{Sample Size Determination}

The sample size was determined using a single population proportion formula $\left(n=(Z \alpha / 2){ }^{2} \mathrm{P}(1-p) \backslash d^{2}\right)$. Prevalence of precancerous lesion is $6.7 \%$, taken from study conducted in Adwa, North Ethiopia, ${ }^{12} 3 \%$ margin of error, 95\% CI were considered to estimate the optimal sample size. Hence, the final sample size was 293.

\section{Sampling Procedure}

Based on a prior month's facility report before data collection, 598 women were reported to have been screened for precancerous lesion. Considering the report as a source population, a sample of 293 was selected using systematic random sampling method. The first study subject was selected by lottery method and then every $2^{\text {nd }}$ woman coming for the test was selected till the required sample size was achieved.

\section{Study Variables}

Independent variable for the study was precancerous lesion.

Socio-demographic characteristics of the study participants like age, marital status, educational level, occupation, religion and average monthly income were used.

Others like number of children, age of first intercourse, number of sexual partners, history of sexual transmitted infections and women's HIV status were also considered as independent variables in the study.

\section{Data Collection Instrument and Procedure}

Questionnaire adapted from similar studies and visual inspection with acetic acid were used to collect data. The questionnaire was prepared in English and then translated to local languages (Afan Oromo and Amharic) by legal translators 
of respective languages, then back translated to English to check for consistency and ensure the quality of translation. ${ }^{13}$

Screening using VIA was done by two already trained midwives who were working at cervical cancer screening and treatment center.

Before performing the VIA test, the procedure was explained to each woman. External genitalia were opened and urethral opening was checked for discharge. Skene's and Bartholin's glands were palpated.

Using speculum, cervix was checked for evidence of infection (cervicitis) such as whitish purulent discharge (mucopus), ectopy (ectropion), grossly apparent tumors or Nabothian cysts, ulcers or "strawberry" lesions (Trichomonas infection). Clean cotton swab was used to remove any discharge, blood or mucus from the cervix. Then, a clean swab in dilute acetic acid solution was soaked and applied to the cervix. This was repeated until the cervix has been thoroughly washed with acid (if necessary) and waited for 2 minutes to observe the cervix for acetowhite changes. Squamo-columnar junction carefully inspected. Cervix was also carefully checked for easily bleeds. The area was carefully inspected for any raised and thickened white plaques or acetowhite epithelium.

During inspection acetic acid swab was reapplied to cervix to remove any mucus, blood or debris that develops as it may obscure the view. At the end of the procedure, a fresh cotton swab was used to remove any remaining acetic acid from the cervix and vagina. For positive VIA test results, women were counseled and linked for immediate treatment. Infection prevention strategies were carefully used throughout and after the procedure.

\section{Data Quality Control}

The questionnaire was pre-tested in 20 women in Bishoftu Hospital which is outside of the study area. Following pretest, necessary modification was made to the questionnaire. Regarding survey questionnaire, two days training was given to data collectors and supervisors on basic technique of conducting interview including research ethical principles.

Supervision was strictly done during data collection and VIA testing. Filled questionnaires were checked for completeness and consistency on daily basis and addressed.

\section{Data Processing and Analysis}

Data was cleaned, coded, entered in to Epi version 7 and exported to SPSS version 20.1 for analysis. Bivariate and multivariate logistic regression analysis was used to measure the association between variables. Variables with P-value $<0.2$ in the bivariate analysis were included in the multivariate logistic regression model. Adjusted odds ratio with its $95 \% \mathrm{CI}$ and $\mathrm{P}$ value less than 0.05 was used to decide about the presence of association.

\section{Operational Definitions}

VIA Positive test result was when raised and thickened white plaques or aceto-white epithelium, usually near Squama-columnar junction is seen while VIA Negative test result was when smooth, pink, uniform and featureless cervix, cervical ectropion, polyp, cervicitis, inflammation and/or cyst after applying dilute solution of acetic acid is seen. $^{7}$

\section{Results}

\section{Socio-Demographic Characteristics of Women Interviewed}

The total of 293 women of reproductive age group who came to Adama Hospital Medical College cervical screening center for cervical cancer screening during study period were included in the study making response rate $100 \%$. The mean ( \pm standard deviation) age of participants was $35.97+5.87$ years old. About $83(28.3 \%)$ participants were in the age range of 36-40 years followed by $82(28 \%)$ who were in the age range of 31-35 years. Close to the half, 139 $(47.4 \%)$ were Orthodox religion followers. With regards to educational status, 109 (37.2\%) had primary education followed by $81(27.6 \%)$ who had no formal education. Around two thirds, 202 (68.9\%), were married. By occupation, 135 (46.1\%) were housewife (Table 1).

\section{Clinical and Sexual Behavior}

All study participants had never been screened for cervical cancer before. About 182 (62.1\%) of the study participants reported that they started their first sex at the age of 18 and above. Three fourths of them, 224 (76.5\%), had never used condom in their lifetime. Forty-five (15.4\%) had history of pelvic infections and $71(24.2 \%)$ had history of sexual transmitted diseases. About 108 (36.9\%) had a history of multiple sexual partners. One hundred and twenty five (43.8\%) were tested positive for HIV (Table 2). 
Table I Socio-Demographic Characteristics of Women Attending Precancerous Cervical Lesion Screening at Adama Hospital Medical College, 2019

\begin{tabular}{|c|c|c|}
\hline Variables & Frequency & Percent \\
\hline \multicolumn{3}{|l|}{ Age (year) } \\
\hline$\leq 30$ & 70 & 23.9 \\
\hline $31-35$ & 82 & 28.0 \\
\hline $36-40$ & 83 & 28.3 \\
\hline$>40$ & 58 & 19.8 \\
\hline \multicolumn{3}{|l|}{ Religion } \\
\hline Orthodox & 139 & 47.4 \\
\hline Muslim & 86 & 29.4 \\
\hline Protestant & 65 & 22.2 \\
\hline Others & 3 & 1.0 \\
\hline \multicolumn{3}{|l|}{ Education } \\
\hline No formal education & 81 & 27.6 \\
\hline Primary $(I-8)$ & 109 & 37.2 \\
\hline Secondary (9-12) & 60 & 20.5 \\
\hline Diploma/above & 43 & 14.7 \\
\hline \multicolumn{3}{|l|}{ Marital status } \\
\hline Married & 202 & 68.9 \\
\hline Not married & 91 & 31.1 \\
\hline \multicolumn{3}{|l|}{ Age at first marriage $(n=285)$} \\
\hline$\leq 18$ & $14 \mid$ & 49.5 \\
\hline$>18$ & 144 & 50.5 \\
\hline \multicolumn{3}{|l|}{ Income (ETB) } \\
\hline$<1000$ & 85 & 29.0 \\
\hline $1000-1999$ & 108 & 36.9 \\
\hline 2000-2999 & 39 & 13.3 \\
\hline$\geq 3000$ & 61 & 20.8 \\
\hline \multicolumn{3}{|l|}{ Occupation } \\
\hline Housewife & 135 & 46.1 \\
\hline Not housewife & 158 & 53.9 \\
\hline
\end{tabular}

\section{Prevalence of Precancerous Cervical Lesion}

Out of the total 293 screened women, 15.7\% (95\% CI: $11.3 \%-20.1 \%$ ) were found to be positive for precancerous cervical lesion (Figure 2).

\section{Factors Associated with Cervical Precancerous Lesions}

Variables with $\mathrm{P}$-value $<0.2$ on bivariate analysis were included in the multivariate logistic regression model. On multivariate analysis, after controlling for the effect of other
Table 2 Clinical and Sexual Behavior of Women Attending Precancerous Cervical Lesion Screening at Adama Hospital Medical College, 2019

\begin{tabular}{|c|c|c|}
\hline Variables & Frequency & Percent \\
\hline \multicolumn{3}{|l|}{ Previously screened for cervical cancer } \\
\hline No & 293 & $100 \%$ \\
\hline Yes & 0 & $0 \%$ \\
\hline \multicolumn{3}{|l|}{ Ever smoked } \\
\hline No & 291 & $99.3 \%$ \\
\hline Yes & 2 & $0.7 \%$ \\
\hline \multicolumn{3}{|l|}{ Age at first sex } \\
\hline$<18$ & 111 & $37.9 \%$ \\
\hline$\geq 18$ & 182 & $62.1 \%$ \\
\hline \multicolumn{3}{|l|}{ Condom use } \\
\hline Always & 10 & $3.4 \%$ \\
\hline Sometimes & 59 & $20.1 \%$ \\
\hline Never & 224 & $76.5 \%$ \\
\hline \multicolumn{3}{|l|}{ History of pelvic infection } \\
\hline No & 248 & $84.6 \%$ \\
\hline Yes & 45 & $15.4 \%$ \\
\hline \multicolumn{3}{|l|}{ History of STI } \\
\hline No & 222 & $75.8 \%$ \\
\hline Yes & 7I & $24.2 \%$ \\
\hline \multicolumn{3}{|l|}{ History of STI in sexual partner } \\
\hline No & 279 & $95.2 \%$ \\
\hline Yes & 14 & $4.8 \%$ \\
\hline \multicolumn{3}{|l|}{ History of genital ulcers } \\
\hline No & 282 & $96.2 \%$ \\
\hline Yes & 11 & $3.8 \%$ \\
\hline \multicolumn{3}{|l|}{ History of genital ulcers in partner } \\
\hline No & 289 & $98.6 \%$ \\
\hline Yes & 4 & $1.4 \%$ \\
\hline \multicolumn{3}{|l|}{ History of HIV testing } \\
\hline No & 3 & $1.0 \%$ \\
\hline Yes & 290 & $99.0 \%$ \\
\hline \multicolumn{3}{|l|}{ HIV test result $(n=290)$} \\
\hline Positive & 127 & $43.8 \%$ \\
\hline Negative & 163 & $56.2 \%$ \\
\hline \multicolumn{3}{|l|}{ Sexual partner } \\
\hline Single & 185 & $63.1 \%$ \\
\hline Multiple & 108 & $36.9 \%$ \\
\hline \multicolumn{3}{|l|}{ Her partner have another partner } \\
\hline No & 185 & $63.1 \%$ \\
\hline Yes & 108 & $36.9 \%$ \\
\hline
\end{tabular}

(Continued) 
Table 2 (Continued).

\begin{tabular}{|l|c|c|}
\hline Variables & Frequency & Percent \\
\hline VIA screening result & & \\
Positive & 46 & $15.7 \%$ \\
Negative & 247 & $84.3 \%$ \\
\hline STI screening result & & \\
Positive & 18 & $6.1 \%$ \\
Negative & 275 & $93.9 \%$ \\
\hline
\end{tabular}

confounding factors, four variables - absence of menses, history of pelvic infection, history of STI, and having partner who had another partner - were found to be significantly associated with precancerous cervical cancer at $p$-value below 0.05 (Table 3).

Odds of having cervical precancerous lesion among women who had no menses were $82 \%$ less likely to develop precancerous cervical lesions compared to those women who had regular menses $(\mathrm{AOR}=0.18: 95 \% \mathrm{CI}: 0.04,0.87$ ). Women who had history of pelvic infection were 2.82 times more likely to have cervical precancerous lesion compared those that did not have history of pelvic infection (AOR = 2.82: 95\% CI: 1.21, 6.59) (Table 3).

Women who had history of STI were 2.65 times more likely to have cervical precancerous lesion compared to their counterparts $[\mathrm{AOR}=2.65: 95 \% \mathrm{CI}: 1.26,5.56$ ). Women who had partner having another sexual partner were 2.41 times more likely to have precancerous cervical lesion compared to those who have single partner (AOR $=2.41: 95 \% \mathrm{CI}$ : 1.08 , 5.38) (Table 3).

\section{Discussion}

The aim of our study was to assess precancerous cervical lesions and associated risk factors among women attending cervical screening at Adama Hospital Medical College, Central Ethiopia, using Visual Inspection with acetic acid (VIA) screening method. From 293 women screened for precancerous cervical lesions, 46 (15.7\%) of them were found to be positive for the lesion. This finding was almost consistent with studies conducted in Addis Ababa (12.8\%), ${ }^{13}$ Yirgalem General Hospital, southern Ethiopia $(16.5 \%)^{14}$ and Jimma model clinic of Family Guidance Associating (12.9\%). ${ }^{15}$

However, findings from our study were higher than a study in Rwanda which showed $5.9 \%$ precancerous cervical lesion among similar study population. ${ }^{16}$ The discrepancy might be due to difference in socio-demographic characteristics of the study participants. Differences in availability or accessibly of screening and treatment services among the two countries may also contribute to the discrepancies between the compared findings. Our finding was also higher than the study conducted in the North part of Ethiopia which showed $6.7 \%$ precancerous cervical lesion. ${ }^{12}$ This could be due to study area and study period difference.

The results of our study highlighted a number of health related risks that could increase the women's chance to develop cervix cancer. The risks are merely inherent to the reproductive health: menstrual history, history of pelvic infection, history sexually transmitted infections, and having partner who had another partner.

In this study, women who did not see menses were $82 \%$ less likely to have precancerous cervical lesion compared to those who had regular menstrual history. This could be attributed to women's practices during menstruation which could expose them to several risks. Materials used for protection during menstruation could contribute to heightened risk of human papillomavirus infections. Studies reported that these practices are potentially harmful. The re-use of washed cloths is particularly risky as the human papillomavirus has been detected in menstrual blood and vaginal discharge. ${ }^{17}$ It is obvious that the association between certain strains of HPV and cervical cancer is already well established. ${ }^{18}$ Disappearance of the menses could also be related to using some type of contraceptive which could reduce/interrupt/prevent women's menses. Finding from other study also stipulated that women who have a hormonal intrauterine device (IUD) may experience lighter or no menses, because Levonorgestrel released from IUD prevents the ovaries from releasing eggs. ${ }^{19}$

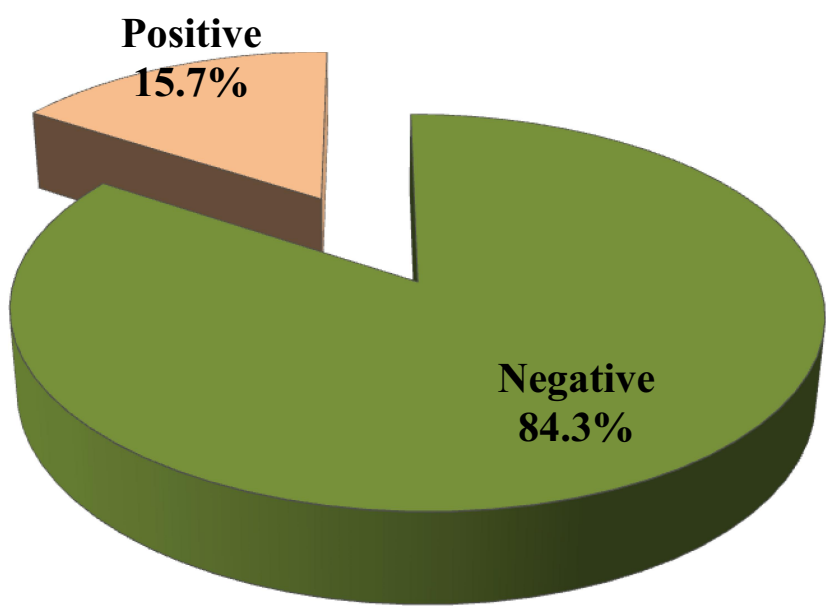

Figure 2 Prevalence of precancerous lesion among women attending precancerous cervical lesion screening at Adama Hospital Medical College, 2019. 
Table 3 Factors Associated to Cervical Precancerous Lesions Among Women Attending Precancerous Cervical Lesion Screening at Adama Hospital Medical College, 2019

\begin{tabular}{|c|c|c|c|c|}
\hline \multirow[t]{2}{*}{ Variables } & \multicolumn{2}{|c|}{ Precancerous Lesion } & \multirow[t]{2}{*}{ COR $(95 \% \mathrm{Cl})$} & \multirow[t]{2}{*}{ AOR $(95 \% \mathrm{Cl})$} \\
\hline & Positive & Negative & & \\
\hline \multicolumn{5}{|l|}{ Marital status } \\
\hline Married & 28 & 174 & 1.00 & 1.00 \\
\hline Not married & 18 & 73 & $1.53(0.79,2.94)$ & $1.28(0.58,2.39)$ \\
\hline \multicolumn{5}{|l|}{ Education } \\
\hline No formal education & 16 & 65 & 1.00 & 1.00 \\
\hline Primary (I-8) & 16 & 93 & $0.70(0.33,1.49)$ & $0.54(0.22,1.29)$ \\
\hline Secondary (9-12) & 7 & 53 & $0.54(0.21,1.40)$ & $0.35(0.12,1.04)$ \\
\hline Diploma/above & 7 & 36 & $0.79(0.29,2.10)$ & $0.73(0.22,2.39)$ \\
\hline \multicolumn{5}{|l|}{ Age at first marriage } \\
\hline$\leq 8$ & 28 & 113 & 1.00 & 1.00 \\
\hline$>18$ & 18 & 126 & $0.58(0.30,1.09)$ & $0.75(0.34,1.59)$ \\
\hline \multicolumn{5}{|l|}{ Occupation } \\
\hline Housewife & 17 & 118 & 1.00 & 1.00 \\
\hline Not housewife & 29 & 129 & $1.56(0.82,2.98)$ & $1.48(0.65,3.35)$ \\
\hline \multicolumn{5}{|l|}{ Menstrual history } \\
\hline Regular & 29 & 156 & 1.00 & 1.00 \\
\hline Irregular & 15 & 56 & I.44(0.72, 2.89) & $1.31(0.61,2.85)$ \\
\hline No menses & 2 & 35 & $0.31(0.07,1.35)$ & $0.18(0.04,0.87)^{*}$ \\
\hline \multicolumn{5}{|l|}{ History of pelvic infection } \\
\hline No & 33 & 215 & 1.00 & 1.00 \\
\hline Yes & 13 & 32 & $2.65(1.26,5.56)$ & $2.82(1.21,6.59)^{*}$ \\
\hline \multicolumn{5}{|l|}{ History of STI } \\
\hline No & 25 & 197 & 1.00 & 1.00 \\
\hline Yes & 21 & 50 & $3.31(1.71,6.39)$ & $2.65(1.26,5.56)^{*}$ \\
\hline \multicolumn{5}{|l|}{ Sexual partner } \\
\hline Single & 18 & 167 & 1.00 & 1.00 \\
\hline Multiple & 28 & 80 & $3.25(1.70,6.22)$ & $2.24(0.99,5.04)$ \\
\hline \multicolumn{5}{|c|}{ Had a partner who have other partner } \\
\hline No & 17 & 168 & 1.00 & 1.00 \\
\hline Yes & 29 & 79 & $3.63(1.88,6.98)$ & $2.42(1.08,5.38)^{*}$ \\
\hline
\end{tabular}

Note: $1.00=$ Reference category, $\mathrm{AOR}^{*}=\mathrm{P}$-value $<0.05$.

On the other hand, study also showed that women who had ever used an intrauterine device (IUD) had a lower risk of cervical cancer. $^{20}$

Finding from this study also showed that women who had history of pelvic infection were more likely to have precancerous cervical lesion compared to those who did not have history of pelvic infection. This could be due to the fact that HPV infection is the known cause for pelvic infection and cervical lesion as well. ${ }^{18,19}$

In our study, women who had history of STI were more likely to have cervical precancerous lesion as compared to those who did not have the infections. This result was supported by study from Swaziland. ${ }^{20}$ This finding was also in agreement with the studies conducted in Ethiopia ${ }^{12,14}$ which identified aceto-white lesion positive women who had been suffering from sexual transmitted diseases. Similarly, this finding was also supported with another study conducted in central part of Ethiopia. $^{21}$ This could be due to the fact that HPV infection is the most common cause of sexually transmitted disease which can also cause cervical lesion. ${ }^{19}$ Study also reported that HPV prevalence was found to be significantly higher among patients with PID, suggesting that patients suffering from PID apparently have a higher risk of cervical cancer. $^{20}$

This study also found that women who had a partner having another sexual partner were more likely to have 
precancerous cervical lesion compared to those who had partner not having another sexual partner. This result was consistent with studies conducted in Swaziland, ${ }^{23}$ Rwanda, ${ }^{16}$ and Ethiopia. ${ }^{13,22}$ This could imply that women who have a sexual partner having another sexual partner have a higher risk of acquiring HPV infection which then causes precancerous cervical lesion.

Visual inspection of the cervix with acetic acid (VIA) is an effective, inexpensive screening test that can be combined with simple treatment procedures for early cervical lesions especially in setting (middle and low income countries) where medical facilities are limited, provided by trained health workers. It is a safe, acceptable, and effective test that can save lives from cervical cancer even in remote areas with few resources. ${ }^{24,25}$ Although VIA reveals precancerous cervical lesion with more accuracy than even a typical Pap smear, yet it also has more false positive test results which could be mentioned as a limitation of our study. ${ }^{25}$ The study was conducted in facility level, which may limit generalizability of the findings to all women, particularly to those in rural areas.

\section{Conclusion}

The magnitude of precancerous cervical lesion among women of reproductive age group at Adama Hospital and Medical College was $15.7 \%$. Menstrual history, history of pelvic infection, having STI, and had sexual partner who have another sexual partner were found to be predictors for precancerous cervical lesion.

\section{Abbreviations}

AIDS, Acquired Immuno Deficiency Syndrome; CC, Cervical Cancer; CCS, Cervical Cancer Screening; CIN, Cervical Intraepithelial Neoplasia; EFMOH, Ethiopia Federal Ministry of Health; HIV, Human Immunodeficiency Virus; HPV, Human Papilloma Virus; HSDP-IV, Health Sector Development Plan-IV; PCCL, Precancerous Cervical Lesion; SCJ, Squamo-Columnar junction; STI, Sexual Transmitted Infections; SVA, Single Visit Approach; VIA, Visual Inspection with acetic acid.

\section{Data Sharing Statement}

Data sets supporting the presented findings were incorporated into the manuscript. For detail contact the corresponding author.

\section{Ethics Approval and Informed Consent}

Ethical clearance was obtained from Arsi University College of health science ethical review board. Permission letter was written to Adama Hospital Medical College Precancerous cervical lesion screening unit. We conducted the study in accordance with the ethical principles of the Declaration of Helsinki. All the study participants were informed about the purpose of the study and written consent was obtained from each before data and sample collection. Participants were also informed that they have full right not to participate or to discontinue at any point in the process of data/sample collection. Each respondent was also assured that information they provided was confidential and used only for the purpose of this study. Study participants whose VIA test result was found to be positive and cancer was suspected, they counseled and linked to treatment center for immediate initiation of the recommended treatment.

\section{Consent for Publication}

Not applicable.

\section{Acknowledgments}

First we would like to thank Adama Hospital and Medical Collage for providing the chance to conduct this study. We would like to also express our deepest appreciation to study participants, data collectors and supervisor for their active and unreserved involvement in the study.

\section{Author Contributions}

All authors made a significant contribution to the work reported, whether that is in the conception, study design, execution, acquisition of data, analysis and interpretation, or in all these areas; took part in drafting, revising or critically reviewing the article; gave final approval of the version to be published; have agreed on the journal to which the article has been submitted; and agree to be accountable for all aspects of the work.

\section{Funding}

The whole research fund was covered by Oromia Regional Health Bureau and authors. However the university had no role in the design of the study, collection, analysis, interpretation of data and in writing the manuscript.

\section{Disclosure}

The authors declare that there is no conflict of interests. 


\section{References}

1. Ethiopia FMoH. National Cancer Control Plan 2016-2020. Ethiopia,Addis Ababa; 2015. Available from: www.iccp-portal.org. Accessed February 20, 2021.

2. World Health Organization. 2014. ComprehensiveCervical Cancer Contro a Guide to Essential Practice. 2nd ed. Geneva. https://www. ncbi.nlm.nih.gov/pubmed/25642554. Accessed February 20, 2021.

3. Bruni L, Albero G, Serrano B, et al. ICO/IARC Information Centre on HPV and Cancer (HPV Information Centre). Human Papillomavirus and Related Diseases in the World. Summary Report 17 June 2019. Available from: https://www.hpvcentre.net/sta tistics/reports/XWX.pdfPDFfile. Accessed February 20, 2021.

4. Pathfinder international. Single-Visit Approach to Cervical Cancer Prevention; Clinical Standards of Practice and Counseling Guidelines. May 2013. Available from: https://www.who.int/pmnch/ media/news/2012/201210. Accessed February 20, 2021.

5. Shiferaw N, Salvador-Davila G, Kassahun K, et al. The single-visit approach as a cervical cancer prevention strategy among women with HIV in Ethiopia: successes and lessons learned. Glob Health Sci Pract. 2016;4(1):87-98. doi:10.9745/GHSP-D-15-00325

6. World Health Organization. WHO Guidelines for Screening and Treatment of Precancerous Lesions for Cervical Cancer Prevention. Geneva; 2013. Available from: www.who.int/reproductivehealth/pub lications/cancers/screening_and_treatment_of_precancerous_lesions/ en/index.html. Accessed February 20, 2021.

7. Federal Democratic Republic of Ethiopia Ministry of Health. Guideline for Cervical Cancer Prevention and Control in Ethiopia January 2015.

8. World Health Organization, Regional Office for South-East Asia. Strategic Framework for the Comprehensive Control of Cancer Cervix in South-East Asia Region. Geneva: World Health Organization, Regional Office for South-East Asia; 2015. Available from: https://apps.who.int/iris/handle/10665/152098. Accessed February 20, 2021.

9. Netsanet A A. Cervical Cancer: ethiopia's Outlook. J Gynecol Women's Health. 2017;5(2):555660. doi:10.19080/JGWH.MS.ID.555660.

10. Pathfider E VIA screening and cryotherapy of cervical cancer for HIV positive women under the project name of "Addis Tesfa" Cervical Cancer prevention (CCP) project. 2009-2014

11. Federal Democratic Republic of Ethiopia Ministry of Health. Health Sector Development Programme IV 2010/11-2014/15. Addis Ababa; 2014. www.healthynewbornnetwork.orghnn-contentuploads.

12. Misgina KH, Belay HS, Abraha TH. Prevalence of precancerous cervical lesion and associated factors among women in North Ethiopia. J Public Health Epidemiol. 2017;9(3):46-50. doi:10.5897/ JPHE2016.0891

13. Teame H, Addissie A, Ayele W, et al. Factors associated with cervical precancerous lesions among women screened for cervical cancer in Addis Ababa, Ethiopia: a case control study. PLoS One. 2018;13(1): e0191506. doi:10.1371/journal.pone.0191506
14. Hailemariam T, Yohannes B, Aschenaki H, et al. Prevalence of cervical cancer and associated risk factors among women attending cervical cancer screening and diagnosis center at Yirgalem General Hospital, Southern Ethiopia. J Cancer Sci Ther. 2017;9(11):730-735. doi:10.4172/1948-5956.1000500

15. Deksissa ZM, Tesfamichael FA, Ferede HA. Prevalence and factors associated with VIA positive result among clients screened at Family Guidance Association of Ethiopia, south west area office, Jimma model clinic, Jimma, Ethiopia 2013: a cross-sectional study. BMC Res Notes. 2015;8:618. doi:10.1186/s13104-015-1594-x

16. Damascène MJ, Nsanzimana S, Aimee MM, Pace LE, Ntaganira J, Riedel RDJ. Prevalence and risk factors for cervical cancer and pre-cancerous lesions in Rwanda. Pan Afr Med J. 2015;12:1. doi:10.11604/pamj.2015.22.26.7116

17. Maree JE, Wright SC. Sexual and menstrual practices: risks for cervix cancer. Health SA Gesondheid. 2007;12(3). doi:10.4102/ hsag.v12i3.265

18. Burd EM. Human Papillomavirus And Cervical Cancer. Clin Microbiol Rev. 2003;16(1):1-17.

19. Jamie Eske, Carolyn Kay. Medically reviewed newsletter;2019 Available from: https://www.medicalnewstoday.com/articles/326543. Accessed February 20, 2021.

20. Skapinyecz J, Smid I, Horváth A, Jeney C, Kardos L, Kovács P. Pelvic inflammatory disease is a risk factor for cervical cancer. Eur J Gynaecol Oncol. 2003;24(5):401-404.

21. America Cancer Society. Cervical Cancer Causes, Risk Factors, and Prevention. cancer.org | 1.800.227.2345 https://www.cancer.org/can cer/cervical-cancer/causes-risks-prevention/risk-factors.html. Accessed February 20, 2021.

22. Kassa RT. Risk factors associated with precancerous cervical lesion among women screened at Marie Stops Ethiopia, Adama town, Ethiopia: a case control study. BMC Res Notes. 2018;11:145. doi:10.1186/s13104-018-3244-6

23. Jolly PE, Mthethwa-Hleta S, Padilla LA, et al. screening, prevalence, and risk factors for cervical lesions among HIV positive and HIV negative women in Swaziland. BMC Public Health. 2017;17:218. doi:10.1186/s12889-017-4120-3

24. Poli UR, Bidinger PD, Gowrishankar S. Visual Inspection with Acetic Acid (VIA) Screening program: 7 years experience in early detection of cervical cancer and pre-cancers in rural South India. Indian J Commun Med. 2015;40(3):203-207. doi:10.4103/09700218.158873

25. Measures Evaluation. Percent of VIA (visual inspection with acetic acid) screenings that test positive. Available from: www.measureeva luation.orgprhcervical-cancer. Accessed February 20, 2021.

\section{Publish your work in this journal}

Cancer Management and Research is an international, peer-reviewed open access journal focusing on cancer research and the optimal use of preventative and integrated treatment interventions to achieve improved outcomes, enhanced survival and quality of life for the cancer patient.
The manuscript management system is completely online and includes a very quick and fair peer-review system, which is all easy to use. Visit http://www.dovepress.com/testimonials.php to read real quotes from published authors. 